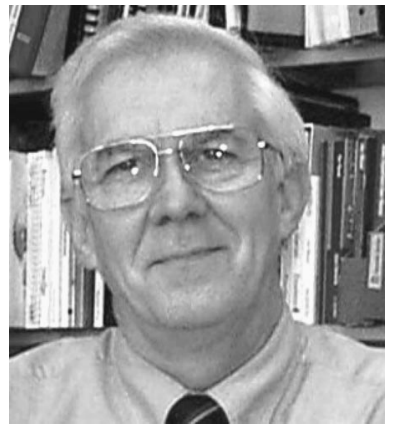

\section{Surfing the Noosphere}

When I was an undergraduate student in physics at the University of Akron, I had a job as a page at the university library. Since I had served as a page at the Firestone branch of the Akron Public Library located across from the main gate of the Firestone Tire and Rubber Company, my campus position was both familiar and invigorating.

In the summer when things went slack, we had time to inventory and reorganize the stacks. It was in the basement stacks that I found leather-bound volumes of the 15 th and 16th centuries-books that I am sure now reside in special climate-controlled vaults. With leather under my fingernails I examined shelf after shelf. On the last pages of volumes that bound London newsweeklies were tabulations of the deaths in the city that year. The numbers, as I remember them now, were in the thousands; they probably included only tradesmen and nobility. They were fascinating as real and immediate connections to a remote past.

During this time my undergraduate education progressed through a series of English classes that required research papers. And there, another miracle of libraries appeared. To support my arguments, to reduce elaborate explanations in favor of some position I had taken, I had only to provide a citation: an author, a volume, a date, and a page. It was a revelation, another way of reaching into the past. Anyone else in the world, if he or she wanted to take the time and make the effort, could go to a library or order a book and follow my argument and check my assertions. I had (still have) a mental image of some unbelieving reader outraged at my assertions accepting a parcel from a courier in the middle of the jungle, opening a string-tied parcel to reveal a book, moving to a desk to check the exact page, finding the reference, and reading it intently.

I doubt anything like that has ever happened. But in the early history of scientific papers and before the age of copy machines and faxes, it was possible. Because the reasons for references are intermingled between the simple need to understand an intriguing result, one's standing in a profession, and claims of priority, a person's attitude toward that list at the end of the paper is understandingly ambiguous. But the value of citations should be clear. They can provide insight into the author's understanding of the field in a way that the text of his or her paper does not. As editor, the references accompanying newly submitted papers provide clues as to the thrust and quality of the articles. Those who have not learned to assess references in papers do not completely understand the research process.

To my mind, the citation of earlier works has another purpose beyond the defense of one's arguments. Individually, it represents simply an effort to get things right with the assistance of others, including, when appropriate, Isaac Newton, Albert Einstein, or Richard Feynman. Some years ago a Jesuit priest and paleontologist, one of the discoverers of the Peking man and other Chinese fossils, contemplated the progress of evolution and tried to understand its progress since the appearance of man on earth. His analysis started with a basic description of the planet as consisting of this hunk of rock, the lithosphere, the air and water that surrounded it, the aquasphere and atmosphere, and of life that emerged from them, the biosphere. But then this Jesuit, Pierre Teilhard de Chardin, postulated another layer, the noosphere $($ noos $=$ mind $)$, the thinking earth. As Teilhard expressed it in his usual elliptical manner:

Understanding, discovery, invention ... From the first awakening of his reflective consciousness, Man has been possessed by the demon of discovery; but until a very recent epoch this profound need remained latent, diffused and unorganised in the human mass ... . In fields embracing every aspect of physical matter, life and thought, the research workers are to be numbered in hundreds of thousands, and they no longer work in isolation but in teams endowed with penetrative powers that it seems nothing can withstand. . . . Research, which until yesterday was a luxury pursuit, is in process of becoming a major, indeed the principal, function of humanity. And our proper biological course, in making use of what we call our leisure, is to devote it to a new kind of work on a higher plane: that is to say, to a general and concerted effort of vision. The Noosphere, in short, is a stupendous thinking machine. (From Revue des Questions Scientifiques 
(Louvain) January 1947, pp. 7-35. Reprinted in "The Future of Man," trans. by Norman Denny, Harper \& Row, New York (1969), pp. 179-180.)

So what you hold in your hand is, in Teilhard's scheme, a piece of the intellectual layer of the planet Earth. From reading his papers it is certain that Teilhard de Chardin, although he died in 1955, clearly understood the import of electronic computers and telecommunications. Had he experienced the Internet, he would have counted it as an additional confirmation of his concept.
The next time you are in the middle of writing a paper or a proposal, trying to puzzle out the importance of someone's results, or evaluating the usefulness or correctness of a paper you are reviewing, consider that in addition to your individual effort, you are, according to Père Teilhard, contributing to an elaborate intellectual construction of which we scientists and engineers are all builders.

Donald C. O'Shea Editor 